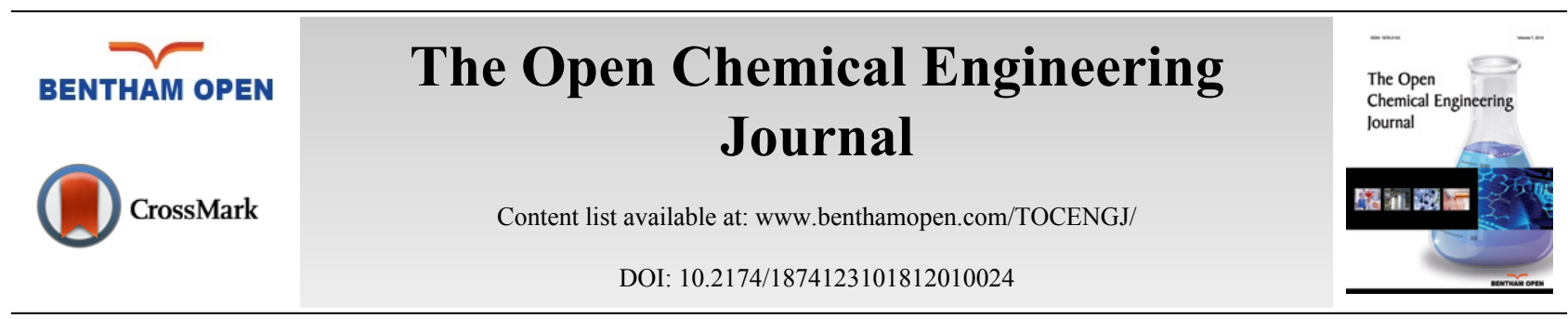

RESEARCH ARTICLE

\title{
Pyrene and Chrysene Tolerance and Biodegradation Capability of Pleurotus Sajor-Caju
}

\author{
Giuliano Saiu ${ }^{1}$, Stefania Tronci, ${ }^{1, *}$, Massimiliano Grosso ${ }^{1}$, Enzo Cadoni ${ }^{3}$ and Nicoletta Curreli ${ }^{2}$ \\ ${ }^{\prime}$ Dipartimento di Ingegneria Meccanica, Chimica e dei Materiali, Università degli Studi di Cagliari, i.e.Marengo 2, \\ 09123 Cagliari, Italy \\ ${ }^{2}$ Dipartimento di Scienze Biomediche, Unità di Biochimica, Università degli Studi di Cagliari, Cittadella Universitaria, \\ 09042 Monserrato, Cagliari, Italy \\ ${ }^{3}$ Dipartimento di Scienze Chimiche e Geologiche, Università degli Studi di Cagliari, Cittadella Universitaria, 09042 \\ Monserrato, Cagliari, Italy
}

Received: January 23, 2018

Revised: March 02, 2018

Accepted: March 12, 2018

\begin{abstract}
:
Introduction:

The present work focused on the biodegradation capability of a white-rot fungus, the Pleurotus sajor-caju, when exposed to polycyclic aromatic hydrocarbons.
\end{abstract}

\section{Methods:}

The research was carried out by using in vitro systems developed on Petri dishes, to evaluate the fungal tolerance to pyrene and chrysene, followed by experiments in liquid medium. The first experimental campaign was necessary to evaluate the conditions promoting fungal growth and tolerance (presence of surfactants, peptone, copper sulphate and lecithin) and it was designed and analysed using statistical techniques.

\section{Results:}

It was found that the fungal population growth is strongly inhibited by chrysene presence. On the other hand, pyrene had a mild negative impact on the mycelia growth, which seemed to be positively influenced by the presence of Tween 80 and copper sulphate. Starting from these results, the behaviour of Pleurotus sajor-caju in presence of pyrene was investigated in liquid medium. Results showed that the depletion of pyrene was evident during a period of 20 days, and removal efficiency was greater than $90 \%$.

Keywords: Bioremediation, PAH, Whiterot fungi, DOE, Carcinogenic, Pleurotus sajor-caju.

\section{INTRODUCTION}

Polycyclic Aromatic Hydrocarbons (PAHs) are considered priority pollutants because of their ubiquity and because most of them are mutagenic and carcinogenic. PAH compounds with high molecular weight show low water solubility and biodegradability ( Table 1) [1], and genotoxicity generally increases as the water solubility decreases. PAHs can be therefore found in soils and sediments, and they persist in the environment. Furthermore, they have a high trophic transfer and biomagnification within the ecosystems due to their lipophilic nature. Among the different strategies developed to remove PAHs from the environment, including volatilization, photo-oxidation, chemical oxidation, and adsorption, biodegradation has recently received great attention [2,3]. The successful use of microorganisms to clean up contaminated environments mainly depends on the low cost of such treatments and the fulfilment of the most

* Address correspondence to this author at the Dipartimento di Ingegneria Meccanica, Chimica e dei Materiali, Università degli Studi di Cagliari, i.e.Marengo 2, 09123 Cagliari; Tel: +39 070 6755050; Fax: +39 070 6755067; E-mail: stefania.tronci@dimcm.unica.it 
important properties required by the current regulations [4, 5].

Table 1. Concentrations $[\mathrm{g} / \mathrm{kg}]$ used for the two-level assessment.

\begin{tabular}{|c|c|c|}
\hline Factor/Level & Low (-1) & High (+1) \\
\hline $\mathrm{X}_{1}=$ pyrene & 0 & $5.0 \times 10^{-3}$ \\
\hline $\mathrm{X}_{2}=$ copper sulphate & 0 & $1.25 \times 10^{-3}$ \\
\hline $\mathrm{X}_{3}=$ peptone & 0 & 10.0 \\
\hline $\mathrm{X}_{4}=$ Tween 80 & 2.5 & 10.0 \\
\hline $\mathrm{X}_{5}=$ lecithin & 0 & 30.0 \\
\hline $\mathrm{X}_{6}=$ chrysene & 0 & $5.0 \times 10^{-3}$ \\
\hline
\end{tabular}

Among the different organisms proposed in literature to be applied for bioremediation [5, 6], white-rot fungi have recently captured the interest of several researchers because of their ability to degrade an extremely diverse range of very persistent or toxic environmental pollutants [7, 8]. In particular, their degradation ability has been assessed under laboratory conditions for pesticides [9], chlorophenols [10], synthetic dyes [11, 12], drugs [13], and PAHs [2, 14 - 16]. The ability to degrade such complex compounds depends on the possibility to produce extracellular enzymes with low substrate specificity, such as lignin peroxidase, laccase, aryl-alcohol-oxidase and manganese peroxidase (cf [17] and reference herein) excreted by the mycelium to degrade lignocellulosic material.

In the present study the ability of the white-rot fungus Pleurotus sajor-caju to degrade PAHs has been investigated. This organism efficiently grows on and degrades a wide range of substrates, such as olive wastewater [18], naphthoquinones [19], and agricultural wastes [20]. Recently, Ipeaiyeda et al. [21] have found that Pleurotus sajor-caju is able to reduce PAHs concentration in a contaminated soil, showing the potentialities of such mycelium.

Unlike other types of white-rot fungi (e.g. Pleurotus ostreatus), the behaviour of Pleurotus sajor-caju when exposed to PAH species has not been deeply investigated [22]. The focus of the present work is to assess mycelium tolerance and biodegradation capabilities in presence of pyrene and chrysene, which are four-ring PAH species. The effects of additives on pollutant bioavailability (addition of Tween 80) and fungal growth (addition of lecithin, peptone and copper sulphate) have been also investigated [23 - 27]. Because of the high number of variables, DoE (Design of Experiments) techniques have been exploited in order to obtain maximal informative data while reducing the number of experiments. The results obtained in solid medium have been then used to carry out an experimental campaign in liquid medium, in order to evaluate the capability of Pleurotous sajor-caju to remove the four-ring pollutant that leads to better results during tolerance tests.

\section{MATERIALS AND METHODS}

\subsection{Microorganism and Material}

Pleurotus sajor-caju was used in mycelial form, starting from a voucher culture permanently preserved at $4{ }^{\circ} \mathrm{C}$ in the collection of the Biochemistry Unit of the department of 'Scienze Biomediche', University of Cagliari.

Agar, malt and yeast extract (microbiological grade), chrysene (purity 99.9\%) and Tween 80 were obtained from Fluka, whereas pyrene (purity $>99 \%$ ), acetonitrile (HPLC grade), dichloromethane (pesticide grade), acetone (pesticide grade) and hexane (analysis grade) from Sigma Aldrich.

\subsection{Tolerance of Pleurotus Sajor-caju to PAHs}

For the experiments on the solid media campaign the strain was inoculated into $9 \mathrm{~cm}$ Petri dishes at $25{ }^{\circ} \mathrm{C}$ with an electronic incubator. Appropriate medium of agar-malt-yeast (AMY) was used. The AMY composition was $2 \%$ of agar, $2 \%$ of malt and $0.5 \%$ of yeast [7] and different concentrations of PAHs (chrysene and pyrene) for each experimental run were used, accordingly with the experimental design explained in detail in Section 3. The inoculum consisted of six millimetres disk plug of fresh mycelium, added in each plate under sterile condition.

In order to improve Pleurotus tolerance, the impact of copper sulphate [23], peptone [24] and soy lecithin [28] were evaluated. Furthermore, Tween 80 was used to enhance bioavailability and aid the biodegradation of pyrene and chrysene [26, 27]. 


\subsection{Biodegradation of Pyrene}

Biodegradation experiments in liquid medium were carried out in 500-ml Erlenmayer flasks with a volume of 250 $\mathrm{ml}$ of medium (base medium: $2 \%$ malt extract, $0.5 \%$ yeast extract). Copper sulphate $(0.05 \mathrm{mM})$ and Tween $80(0.75 \%)$ were also added to the medium along with pyrene ( 5 or $10 \mathrm{ppm})$. As for tolerance experiments, $6 \mathrm{~mm}$ plugs of fresh mycelium were added under sterile condition to the medium. Cultures were incubated for 50 days in an orbital shaker at $25^{\circ} \mathrm{C}$ and $300 \mathrm{rpm}$. Samples were withdrawn at different days to monitor pyrene biodegradation. All experiments were carried out in duplicate and two more control runs, containing only malt and agar, were performed.

\subsection{Analytical Methods}

\subsubsection{Fungal Growth Determination}

In order to monitor mycelium growth, photos were taken every day using a high resolution camera (Canon EOS 50d). Every photo was shot in raw format, converted in jpg format and then properly post-processed by means of Adobe $^{\circledR}$ Photoshop ${ }^{\circledR}$. Finally, the pictures were binarized and the mycelium area was computed with the aid of a Matlab ${ }^{\circledR}$ code. Fig. (1) shows the picture of a Petri dish (a) and the selected mycelium in black (b) used to compute the area of fungi.

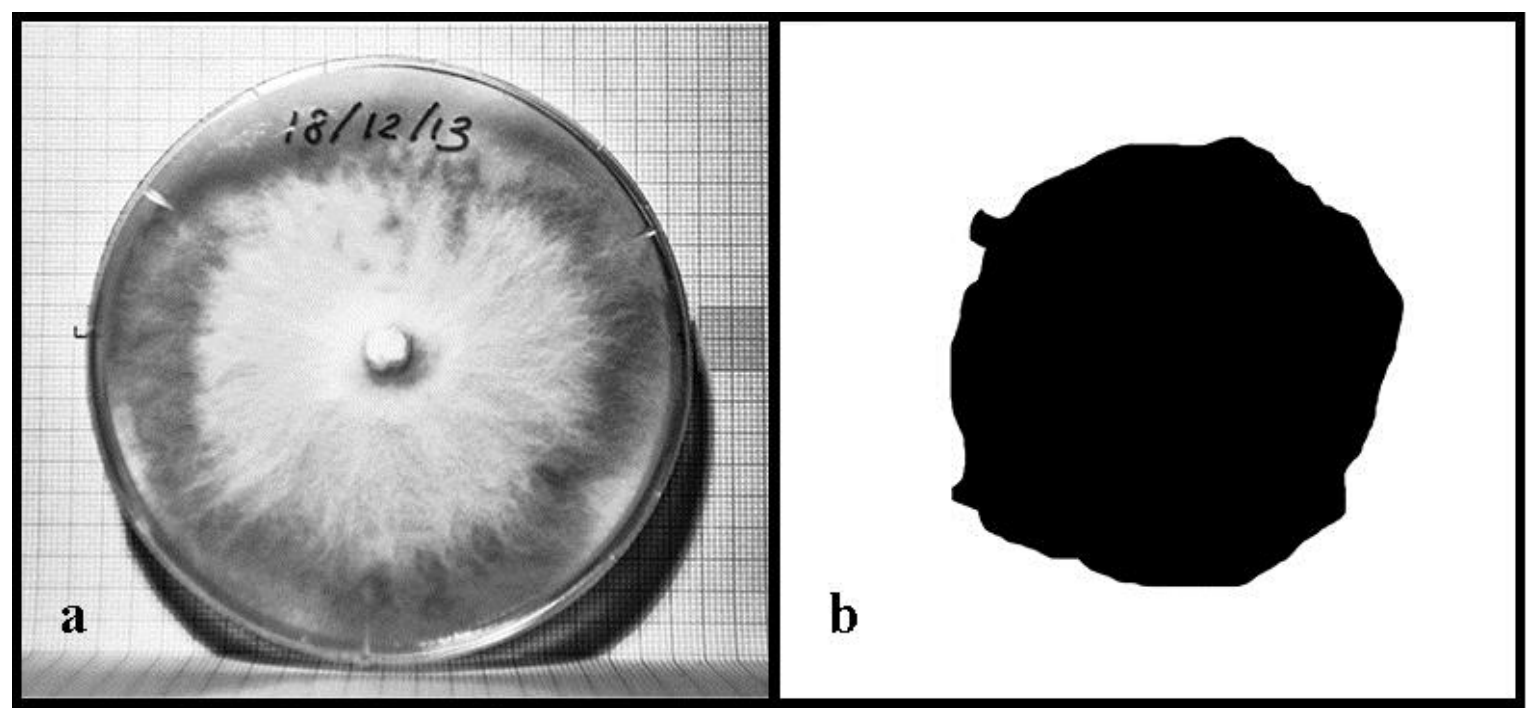

Fig. (1). Mycelium growth determination: (a) picture of the Petri dish containing the grown mycelium, and (b) processed image.

\subsubsection{Pyrene and Products Analysis}

Aliquots of $4 \mathrm{ml}$ of the suspension containing broth and mycelium were taken over time and filtered through a 0.22 $\mu \mathrm{m}$ filter and then analysed by high performance liquid chromatography. The EPA 8310 method was used with the following equipment: Agilent 1200 infinity LC system and column Zorbax Eclipse plus C18 $(4.6 \cdot 100 \mathrm{~mm}, 3.5 \mu \mathrm{m}$ particle size). Elution was performed using a two solvents gradient ( $\mathrm{A}=$ water $-\mathrm{B}=$ acetonitrile): the elution started with $40 \%$ of B followed by a linear gradient to $95 \%$ of B. The injection volume was $5 \mu 1$, and detection was performed through DAD at 230, 240, 254, 270, $350 \mathrm{~nm}$ with $400 \mathrm{~nm}$ reference wavelength and spectrum acquisition.

Another sample of $1 \mathrm{ml}$ with the suspended mycelium was separated by centrifugation and then treated as a solid. The mycelium was extracted using an accelerated solvent extractor, Dionex ASE 300, with the following operating condition: $100{ }^{\circ} \mathrm{C}, 1500 \mathrm{psi}$, heat $5 \mathrm{~min}$, static $5 \mathrm{~min}$, flush $60 \%$, purge $60 \mathrm{sec}$, cycles 1 , solvent acetonedichloromethane $1: 1$. The extract was concentrated in a rotavapor $\left(\mathrm{Buchi}^{\circledR}\right)$ and then taken up with hexane before the analysis that was performed with an Agilent GC/MS system. The analysis conditions were the following: oven from 50 ${ }^{\circ} \mathrm{C}$ to $100{ }^{\circ} \mathrm{C}$ at a rate of $30^{\circ} \mathrm{C} / \mathrm{min}, 100^{\circ} \mathrm{C}$ hold for $2 \mathrm{~min}$, then a ramp at rate of $10^{\circ} \mathrm{C} / \mathrm{min}$ to $320^{\circ} \mathrm{C}$, hold for $3 \mathrm{~min}, 1$ $\mu 1$ splitless injection, injector at $250^{\circ} \mathrm{C}-9.79 \mathrm{psi}$, column flow $1.2 \mathrm{ml}$ with helium, column Agilent HP-5 - $30 \mathrm{~m}-250$ $\mu \mathrm{m}-0.25 \mu \mathrm{m}$. Mass spectrometer in total scan, 45-350 amu. 


\section{EXPERIMENTAL DESIGN FOR IN VITRO BEHAVIOUR}

\subsection{Factorial Design}

The first step of this investigation was devoted to assess Pleurotus sajor-caju tolerance towards the selected fourring PAH compounds, namely chrysene and pyrene. These chemical species were selected because they showed low bioavailability and recalcitrance. The behaviour of the Pleurotus strain was thus monitored by jointly varying 6 factors, which were the concentrations of pyrene $\left(\mathrm{X}_{1}\right)$, copper sulphate $\left(\mathrm{X}_{2}\right)$, peptone $\left(\mathrm{X}_{3}\right)$, Tween $80\left(\mathrm{X}_{4}\right)$, soy lecithin $\left(\mathrm{X}_{5}\right)$, and chrysene $\left(\mathrm{X}_{6}\right)$. Two levels of the variables were considered as reported in Table 1.

A full factorial design for the study of the six different factors should require $2^{6}$ different combinations of experimental conditions. Thus, it should require a large amount of resources in estimations of the interaction terms between factors. As the number of factors increases, the ratio of the number of main effects to the total number of effects rapidly diminishes. For instance, in the full $2^{6}$ experiments with 64 test runs, only $9.5 \%$ of the effects calculated are the main effects. The remaining $90.5 \%$ of the estimates are devoted to interaction effects, many of which are not likely to be of statistical or practical importance [28]. The use of fractional factorial designs is generally used to overcome this problem and it replaces some of the high-order interactions terms by an additional experimental factor. Starting from the design matrix, high-order interactions between factors $\mathrm{X}_{1}, \mathrm{X}_{2}$, and $\mathrm{X}_{3}$ are created by multiplying the corresponding entries in columns $\mathrm{X}_{1}, \mathrm{X}_{2}$, and $\mathrm{X}_{3}$ to obtain a new column $\mathrm{X}_{1} \cdot \mathrm{X}_{2} \cdot \mathrm{X}_{3}$. In fractional design, an additional factor $\mathrm{X}_{4}$ is assigned to that column $\mathrm{X}_{1} \cdot \mathrm{X}_{2} \cdot \mathrm{X}_{3} \cdot \mathrm{X}_{4}$ and $\mathrm{X}_{1} \cdot \mathrm{X}_{2} \cdot \mathrm{X}_{3}$ are said to be aliased of one another. This type of fractional design is referred as $2^{\mathrm{k}-\mathrm{p}}$, where $\mathrm{p}$ is the number of factors aliased, obtaining a substantial reduction in the required number of experimental runs. The main drawback of such method is that it could be difficult to clearly distinguish some of the effects from one other, i.e. assigning $X_{4}$ to the $X_{1} \cdot X_{2} \cdot X_{3}$ column implies that the $X_{4}$ effect is confounded with the $\mathrm{X}_{1} \cdot \mathrm{X}_{2} \cdot \mathrm{X}_{3}$ effect. If the latter effect can be considered negligible, then the observed effect can be attributed to $\mathrm{X}_{4}$. Fractional factorial designs are very helpful for a preliminary understanding of a given process, because they allow for the separation of the important effects from the unimportant ones at an early stage of experimentation. In this work a two level, six factors, one-quarter fraction factorial design, with resolution IV ( $\left.2_{I V}^{6-2}\right)$ was used [29], leading to 16 different experimental conditions describing the influence of 6 parameters. Every treatment was repeated three times and three more control runs (with only AMY) have been also performed, leading to a total of 51 experiments.

The coded scheme used to describe the factor levels is based on the +1 and -1 signs, where +1 denotes the high level of a factor and -1 the low level (Table 1). Table 2 summarizes the experiments according to the fractal design obtained by means of the Franklin-Bailey algorithm [30]. The generators of the fractional design and the alias structure are reported in Table 3 , where it is shown that $\mathrm{X}_{5}$ and $\mathrm{X}_{6}$ can be respectively confounded with $\mathrm{X}_{2} \cdot \mathrm{X}_{3} \cdot \mathrm{X}_{4}$ and $\mathrm{X}_{1} \cdot \mathrm{X}_{3} \cdot \mathrm{X}_{4}$ effects. In absence of detailed information on the system under investigation, triple effects will be considered negligible and the observed effects will be assigned to the lecithin $\left(\mathrm{X}_{5}\right)$ and chrysene $\left(\mathrm{X}_{6}\right)$.

Table 2. Fractional factorial design $2_{I V}^{6-2}$.

\begin{tabular}{|c|c|c|c|c|c|c|}
\hline \multirow{2}{*}{ Run } & \multicolumn{6}{|c|}{ Factors } \\
\hline & $\overline{X_{1}}$ & $\mathbf{X}_{2}$ & $X_{3}$ & $\overline{X_{4}}$ & $X_{5}$ & $\overline{X_{6}}$ \\
\hline 1 & -1 & -1 & -1 & -1 & -1 & -1 \\
\hline 2 & -1 & -1 & -1 & 1 & 1 & 1 \\
\hline 3 & -1 & -1 & 1 & -1 & 1 & 1 \\
\hline 4 & -1 & -1 & 1 & 1 & -1 & -1 \\
\hline 5 & -1 & 1 & -1 & -1 & 1 & -1 \\
\hline 6 & -1 & 1 & -1 & 1 & -1 & 1 \\
\hline 7 & -1 & 1 & 1 & -1 & -1 & 1 \\
\hline 8 & -1 & 1 & 1 & 1 & 1 & -1 \\
\hline 9 & 1 & -1 & -1 & -1 & -1 & 1 \\
\hline 10 & 1 & -1 & -1 & 1 & 1 & -1 \\
\hline 11 & 1 & -1 & 1 & -1 & 1 & -1 \\
\hline 12 & 1 & -1 & 1 & 1 & -1 & 1 \\
\hline 13 & 1 & 1 & -1 & -1 & 1 & 1 \\
\hline
\end{tabular}


(Table $\square$ ) contd.....

\begin{tabular}{|c|c|c|c|c|c|c|}
\hline \multirow{2}{*}{ Run } & \multicolumn{7}{|c|}{ Factors } \\
\cline { 2 - 7 } & $\mathbf{X}_{\mathbf{1}}$ & $\mathbf{X}_{\mathbf{2}}$ & $\mathbf{X}_{\mathbf{3}}$ & $\mathbf{X}_{\mathbf{4}}$ & $\mathbf{X}_{\mathbf{5}}$ & $\mathbf{X}_{\mathbf{6}}$ \\
\hline 14 & 1 & 1 & -1 & 1 & -1 & -1 \\
\hline 15 & 1 & 1 & 1 & -1 & 1 & -1 \\
\hline 16 & 1 & 1 & 1 & 1 \\
\hline
\end{tabular}

Table 3. Generators and alias structure, up to third degree interactions.

\begin{tabular}{|c|c|c|c|}
\hline- & \multicolumn{3}{|c|}{ Terms } \\
\hline Generators & $\mathrm{X}_{5}=\mathrm{X}_{2} \cdot \mathrm{X}_{3} \cdot \mathrm{X}_{4}$ & $\mathrm{X}_{6}=\mathrm{X}_{1} \cdot \mathrm{X}_{3} \cdot \mathrm{X}_{4}$ & - \\
\hline Defining relations & $\mathrm{I}=\mathrm{X}_{2} \cdot \mathrm{X}_{3} \cdot \mathrm{X}_{4} \cdot \mathrm{X}_{5}$ & $\mathrm{I}=\mathrm{X}_{1} \cdot \mathrm{X}_{3} \cdot \mathrm{X}_{4} \cdot \mathrm{X}_{6}$ & $\mathrm{I}=\mathrm{X}_{1} \cdot \mathrm{X}_{2} \cdot \mathrm{X}_{5} \cdot \mathrm{X}_{6}$ \\
\hline & $\mathrm{X}_{1}+\mathrm{X}_{2} \cdot \mathrm{X}_{5} \cdot \mathrm{X}_{6}+\mathrm{X}_{3} \cdot \mathrm{X}_{4} \cdot \mathrm{X}_{6}$ & $\mathrm{X}_{2}+\mathrm{X}_{1} \cdot \mathrm{X}_{5} \cdot \mathrm{X}_{6}+\mathrm{X}_{3} \cdot \mathrm{X}_{4} \cdot \mathrm{X}_{5}$ & $\mathrm{X}_{3}+\mathrm{X}_{1} \cdot \mathrm{X}_{4} \cdot \mathrm{X}_{6}+\mathrm{X}_{2} \cdot \mathrm{X}_{4} \cdot \mathrm{X}_{5}$ \\
& $\mathrm{X}_{4}+\mathrm{X}_{1} \cdot \mathrm{X}_{3} \cdot \mathrm{X}_{6}+\mathrm{X}_{2} \cdot \mathrm{X}_{3} \cdot \mathrm{X}_{5}$ & $\mathrm{X}_{4}+\mathrm{X}_{1} \cdot \mathrm{X}_{3} \cdot \mathrm{X}_{6}+\mathrm{X}_{2} \cdot \mathrm{X}_{3} \cdot \mathrm{X}_{5}$ & $\mathrm{X}_{6}+\mathrm{X}_{1} \cdot \mathrm{X}_{2} \cdot \mathrm{X}_{5}+\mathrm{X}_{1} \cdot \mathrm{X}_{3} \cdot \mathrm{X}_{4}$ \\
& $\mathrm{X}_{1} \cdot \mathrm{X}_{4}+\mathrm{X}_{3} \cdot \mathrm{X}_{6}$ & $\mathrm{X}_{1} \cdot \mathrm{X}_{5}+\mathrm{X}_{2} \cdot \mathrm{X}_{6}$ & $\mathrm{X}_{1} \cdot \mathrm{X}_{6}+\mathrm{X}_{2} \cdot \mathrm{X}_{5}+\mathrm{X}_{3} \cdot \mathrm{X}_{4}$ \\
& $\mathrm{X}_{2} \cdot \mathrm{X}_{3}+\mathrm{X}_{4} \cdot \mathrm{X}_{5}$ & $\mathrm{X}_{4}+\mathrm{X}_{3} \cdot \mathrm{X}_{6}$ & \\
\hline
\end{tabular}

\subsection{Data Analysis for Tolerance}

PAH tolerance data were fitted by considering the Gompertz model [31, 32], which demonstrated to adequately describe the growth dynamics. The model is reported in Eq. (1)

$$
\frac{d A}{d t}=\mu \cdot A(\log k-\log A) \text {. }
$$

where $A$ is the mycelium population, $\mu$ is the specific growth rate and $k$ is the carrying capacity (i.e. the asymptotic value as $t \rightarrow \infty)$.

Data analysis was developed assuming that the measured area was a reasonable estimation of the mycelium population. Model parameter estimation was performed for each experimental run by means of nonlinear regression libraries, provided by Matlab ${ }^{\circledR}$. Model performances were evaluated using the adjusted determination coefficient $R_{a d j}^{2}$ reported in Eq. (2)

$$
R_{a d j}^{2}=1-\frac{\frac{1}{n-p} \sum_{1}^{n}\left(A_{i}-\widehat{A}_{i}\right)^{2}}{\frac{1}{n-1} \sum_{1}^{n}\left(A_{i}-A\right)^{2}}
$$

where $n$ is the number of experimental data collected at each experimental condition, $p$ is the number of model parameters, $A_{\mathrm{i}}$ is the $i$-th experimental point, $\widehat{A_{l}}$ is the model predicted value at the $i$-th point and $\bar{A}$ is the average value of the measurements. The quality of fit increases as $R_{a d j}^{2}$ tends to unity.

The experiment responses used to evaluate fungal tolerance when exposed to PAHs were the specific growth rate $\mu$ calculated with Eq. (1), the mycelium area at $10 d$, which is strictly related to the lag phase, and the maximum area observed for each experiment.

\section{RESULTS AND DISCUSSION}

\subsection{Tolerance Assessment}

The mycelium growth rate in the Petri dishes was monitored by calculating the fungal area, as reported in Section 2 . Data obtained in the solid medium were described by means of Gompertz model obtaining adjusted determination coefficient $R_{a d j}^{2}$ spanning from 0.33 (minimum value) to 0.99 (maximum value), with an average value equal to 0.89 and median equal to 0.95. Fig. (2) shows some representative comparisons between experimental data and model prediction for different experimental conditions. 

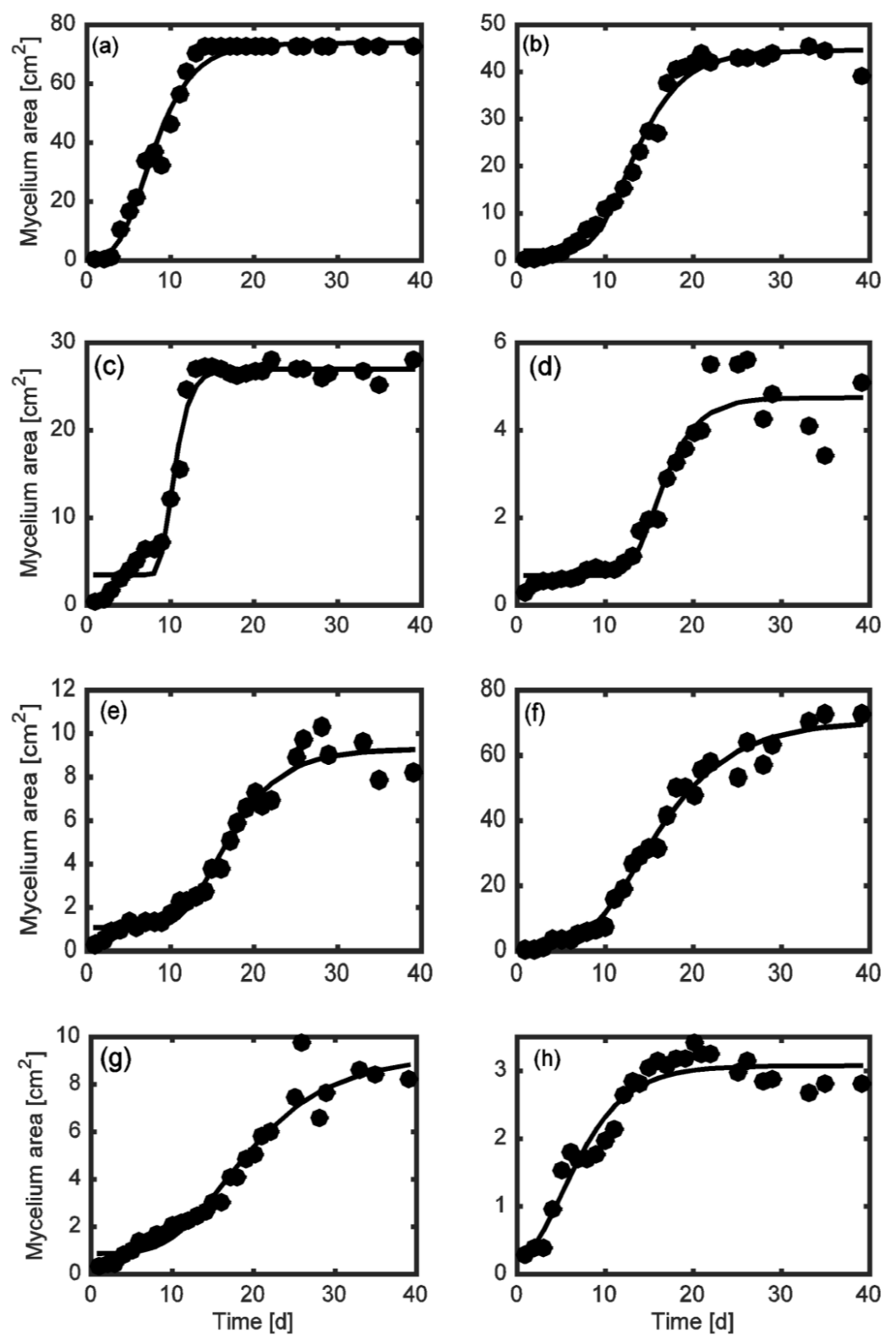

Fig. (2). Comparison between experimental data (black circle) and model prediction (black line) for the control (a) and for the following conditions (Table 2): (b) Run 2; (c) Run 3; (d) Run 8; (e) Run 9; (f) Run 11; (g) Run 13; (h) Run 16.

ANOVA test was performed on $\mu$, and the obtained results are reported in Table 4. In more details, for each source of variation (reported on the column 1), the table shows the corresponding sum of squares of the source variation (column 2), the degrees of freedom d.o.f. (column 3), the mean squared error (column 4), the F-ratio statistics (column 5 ) and the $p$-value associated to that source of variation (column 6). The F-ratio determines whether the variability among group means is larger than the variability of the observations within the groups, while the $p$-value is a probability that measures the evidence against the null hypothesis. Higher F-ratio and lower $p$-value provide stronger evidence that such factor affects the mycelium growth. Significant factors $(i . e$. with a $p$-value $<0.05)$ are highlighted with the asterisk. It was found that, when considering the single effect, peptone, copper sulphate, Tween 80 and chrysene statistically affect mycelium growth. Furthermore, the interactions peptone-chrysene $\left(\mathrm{X}_{3} \mathrm{X}_{6}\right)$ and copper sulphate-chrysene $\left(\mathrm{X}_{2} \mathrm{X}_{6}\right)$ are statistically significant. Those interactions could be confounded with pyrene-Tween 80 $\left(\mathrm{X}_{1} \mathrm{X}_{4}\right)$ and pyrene-lecithin $\left(\mathrm{X}_{1} \mathrm{X}_{5}\right)$, as reported in Table $\mathbf{3}$, but such interpretation of the statistical analysis seems less probable because data related to the single effects indicate no impact of $X_{1}$ and $X_{5}$. 
Table 4. Analysis of variance for the mycelium growth. All the scalars in table are dimensionless.

\begin{tabular}{|c|c|c|c|c|c|}
\hline Source of Variation & Sum of Squares & $\begin{array}{c}\text { Degrees of } \\
\text { Freedom }\end{array}$ & Mean Square Error & F-Ratio & $P$-Value \\
\hline $\mathrm{X}_{1}$ & 5.102 & 1 & 5.102 & 0.79 & 0.388 \\
\hline $\mathrm{X}_{2}{ }^{*}$ & 70.514 & 1 & 70.514 & 10.87 & 0.005 \\
\hline $\mathrm{X}_{3}{ }^{*}$ & 183.003 & 1 & 183.003 & 28.22 & 0.000 \\
\hline $\mathrm{X}_{4}{ }^{*}$ & 52.208 & 1 & 52.208 & 8.05 & 0.012 \\
\hline $\mathrm{X}_{5}$ & 1.613 & 1 & 1.613 & 0.25 & 0.625 \\
\hline $\mathrm{X}_{6}{ }^{*}$ & 127.034 & 1 & 127.034 & 19.59 & 0.000 \\
\hline $\mathrm{X}_{1} \mathrm{X}_{2}$ & 0.033 & 1 & 0.033 & 0.01 & 0.944 \\
\hline $\mathrm{X}_{1} \mathrm{X}_{3}$ & 13.614 & 1 & 13.614 & 2.10 & 0.167 \\
\hline $\mathrm{X}_{3} \mathrm{X}_{6}\left(\mathrm{X}_{1} \mathrm{X}_{4}\right)^{*}$ & 43.596 & 1 & 43.596 & 6.72 & 0.020 \\
\hline $\mathrm{X}_{2} \mathrm{X}_{6}\left(\mathrm{X}_{1} \mathrm{X}_{5}{ }^{*}\right.$ & 71.441 & 1 & 71.441 & 11.02 & 0.004 \\
\hline $\mathrm{X}_{1} \mathrm{X}_{6}$ & 10.513 & 1 & 10.513 & 1.62 & 0.221 \\
\hline $\mathrm{X}_{2} \mathrm{X}_{3}$ & 25.927 & 1 & 25.927 & 4.00 & 0.063 \\
\hline $\mathrm{X}_{2} \mathrm{X}_{4}$ & 0.097 & 1 & 0.097 & 0.01 & 0.904 \\
\hline $\mathrm{X}_{1} \mathrm{X}_{2} \mathrm{X}_{3}$ & 7.855 & 1 & 7.855 & 1.21 & 0.287 \\
\hline $\mathrm{X}_{1} \mathrm{X}_{2} \mathrm{X}_{4}{ }^{*}$ & 38.26 & 1 & 38.26 & 5.90 & 0.027 \\
\hline Residual error & 103.748 & 16 & 6.484 & - & - \\
\hline Pure error & 103.748 & 16 & 6.484 & - & - \\
\hline Total & 754.557 & 31 & - & - & - \\
\hline
\end{tabular}

The dependence of the parameter $\mu$ on the process conditions can be described by the relationship reported in Eq. (3), where the variables are in coded units and only the significant effects selected with the ANOVA test are taken into account. Eq. (3) can be used to estimate the mycelium growth rate, and it is written with the terms in order of significance.

$$
\begin{aligned}
& \mu=3.564-2.391 \cdot X_{3}-1.992 \cdot X_{6}-1.494 \cdot X_{2} X_{6}+1.484 \cdot X_{2}+1.277 \cdot X_{4}+1.167 \cdot X_{3} X_{6}+ \\
& 1.093 \cdot X_{1} X_{2} X_{4}
\end{aligned}
$$

It can be easily seen that peptone $\left(\mathrm{X}_{3}\right)$ and chrysene $\left(\mathrm{X}_{6}\right)$ strongly reduce the mycelium growth rate, whereas copper $\left(\mathrm{X}_{2}\right)$ and Tween $80\left(\mathrm{X}_{4}\right)$ enhance the response in the range of concentration explored. Also two $\left(\mathrm{X}_{3} \mathrm{X}_{6}\right.$ and $\left.\mathrm{X}_{1} \mathrm{X}_{5}\right)$ and three factor $\left(\mathrm{X}_{1} \mathrm{X}_{2} \mathrm{X}_{4}\right)$ interactions significantly contribute to the mycelium growth. The adjusted determination coefficient was estimated, obtaining $R_{a d j}^{2}=82.24 \%$.
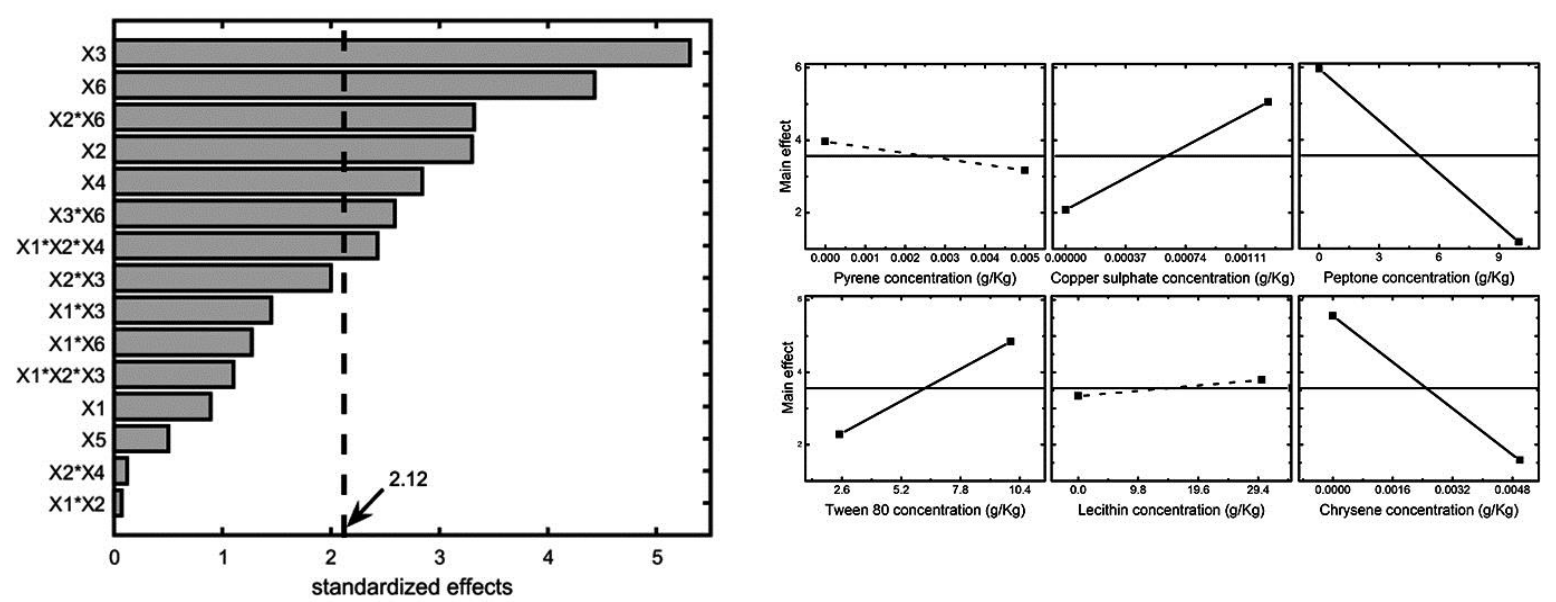

Fig. (3). Left panel: Pareto chart of standardized effects for the $\mu$ parameter (significance threshold - alpha=0.05). Right panel: Main effects on the specific growth rate $\mu$. Significant effects are reported with solid line, not significant effects with dashed line. 
Results can also be easily visualized by means of the Pareto chart, shown in Fig. (3) (left panel), where the significance threshold value (with a significance level $\alpha=0.05$ ) is reported with the solid line. The terms of the chart were calculated using the Yates algorithm [33] and results confirmed that peptone, chrysene, copper sulphate, and Tween 80, along with the interactions chrysene - copper sulphate and chrysene - peptone mainly affect the system. On the other hand, pyrene and lecithin do not significantly influence mycelium growth, meaning that the former seems well tolerated by Pleurotus sajor-caju, while the latter does not enhance fungal growth. For sake of completeness, the main effects are represented in the right panel of Fig. (3), where it is shown that: (i) copper and Tween 80 positively affect the system response; (ii) peptone and chrysene strongly inhibit the fungus growth and (iii), pyrene (slight negative impact) and lecithin (slight positive impact) are not statistically significant.

The significant interactions between the factors are reported in Fig. (4), which shows the detrimental effect of chrysene and peptone on the mycelium growth, whereas copper sulphate can slightly improve Pleurotus tolerance in presence of low pollutant concentrations.
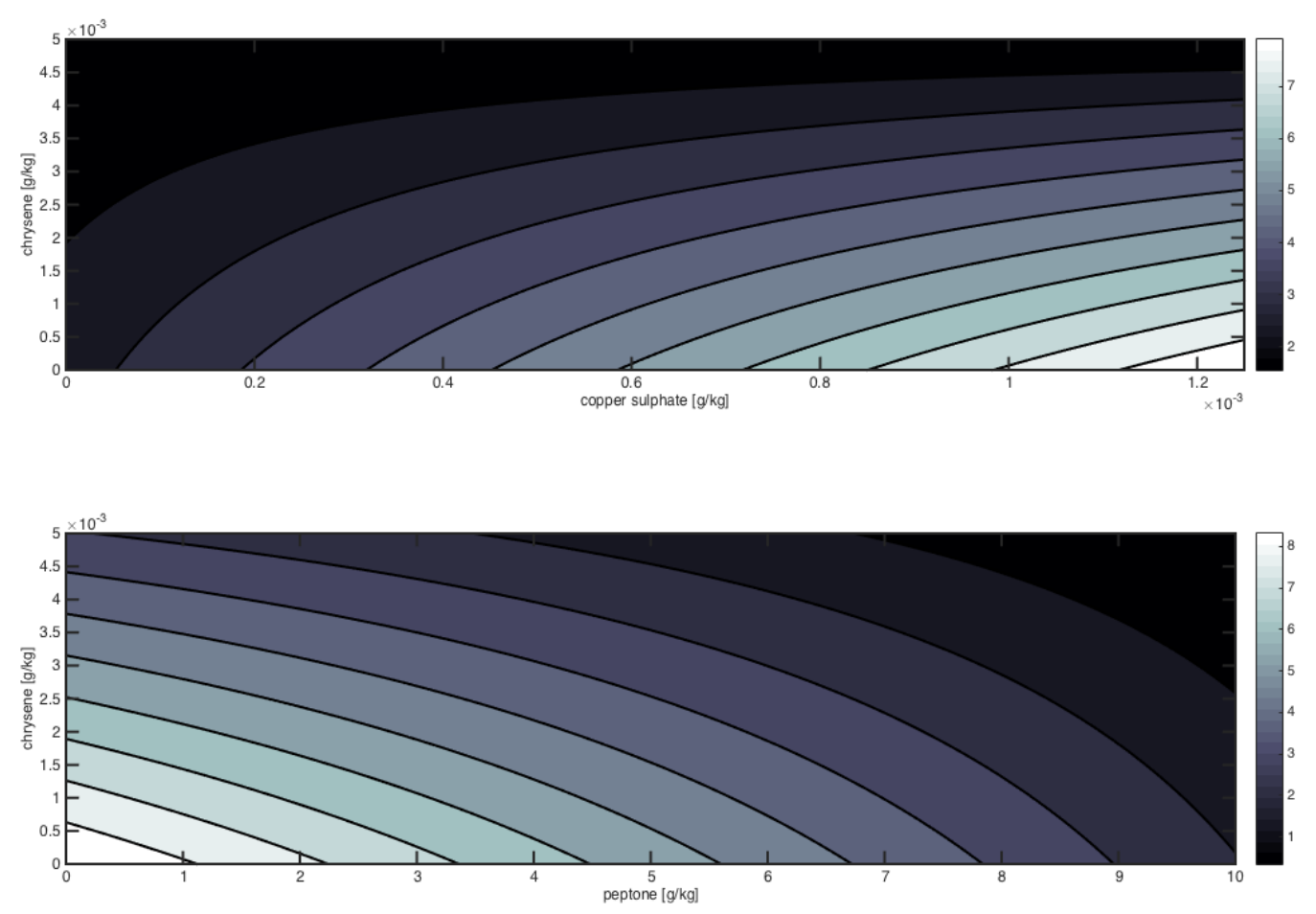

Fig. (4). Contour plot for the interactions of copper sulphate - chrysene (upper panel) and peptone - chrysene (lower panel).
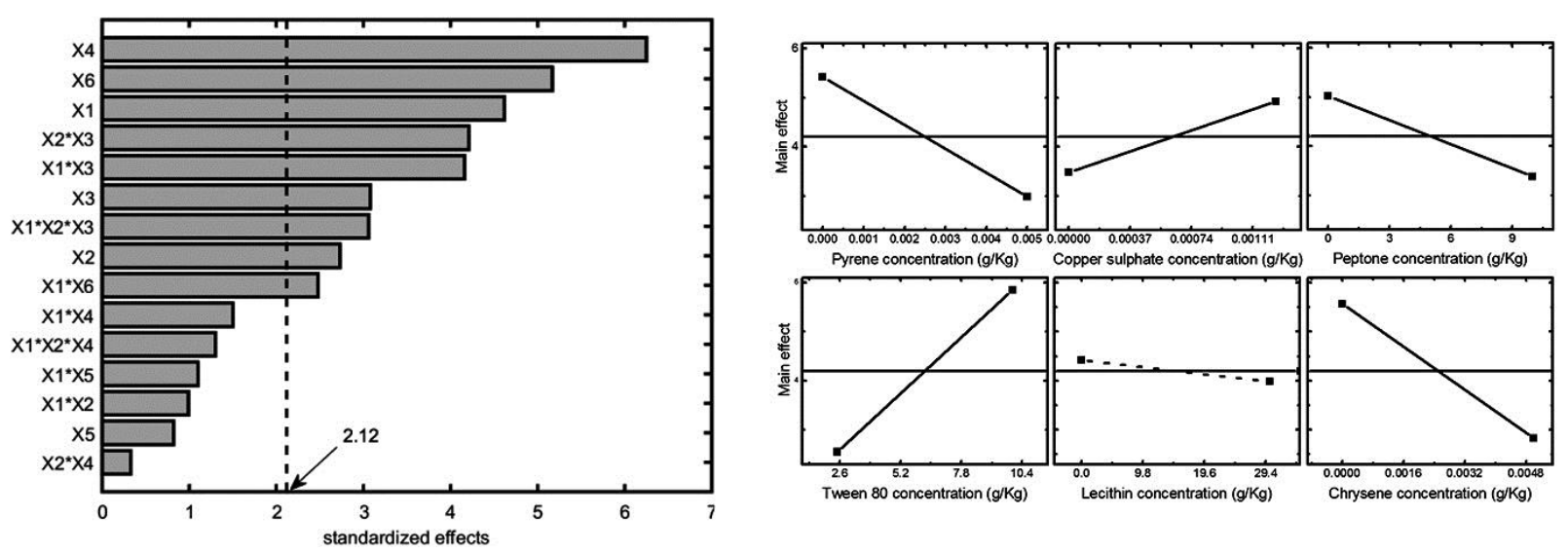

Fig. (5). Left panel: Pareto chart for the mycelium area at $10 d$ (significance threshold - alpha=0.05). Right panel: Main effects on the mycelium area at $10 \mathrm{~d}$. Significant effects are reported with solid line, not significant effects with dashed line. 
Statistical analysis was also performed considering two other experiment outputs: mycelium area at $10 d$ and the maximum area observed for each experiment. The former one was selected because it gave a good estimation of the organism adaptation to growth conditions. The results in terms of Pareto chart and single main effects are reported in Figs. (5-6), and they confirm the detrimental effect of peptone and chrysene on mycelia growth, while a significant unfavourable effect of pyrene can be evidenced when considering the area at $10 \mathrm{~d}$. Conversely, the maximum area is less affected by pyrene, indicating that the organism needed time to adapt to such pollutant, but then it was able to grow showing a better tolerance towards chrysene.
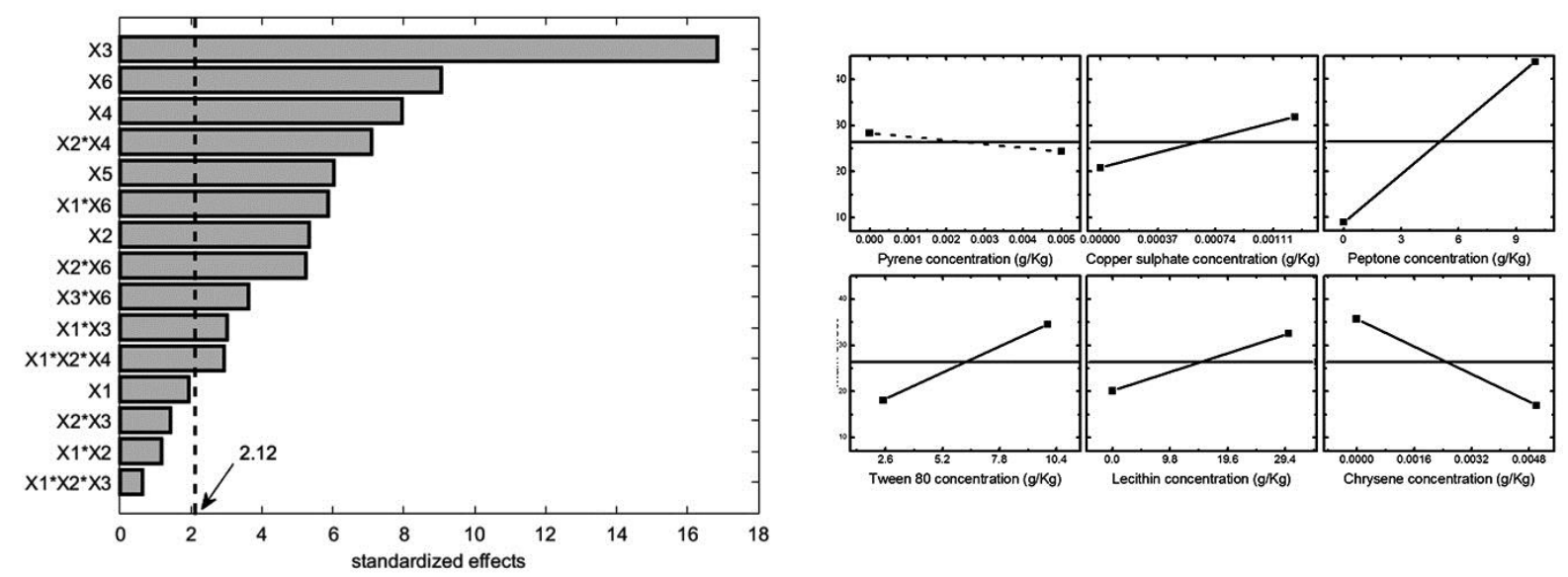

Fig. (6). Left panel: Pareto chart for maximum area (significance threshold - alpha=0.05). Right panel: main effect for the maximum area. Significant effects are reported with solid line, not significant effects with dashed line.
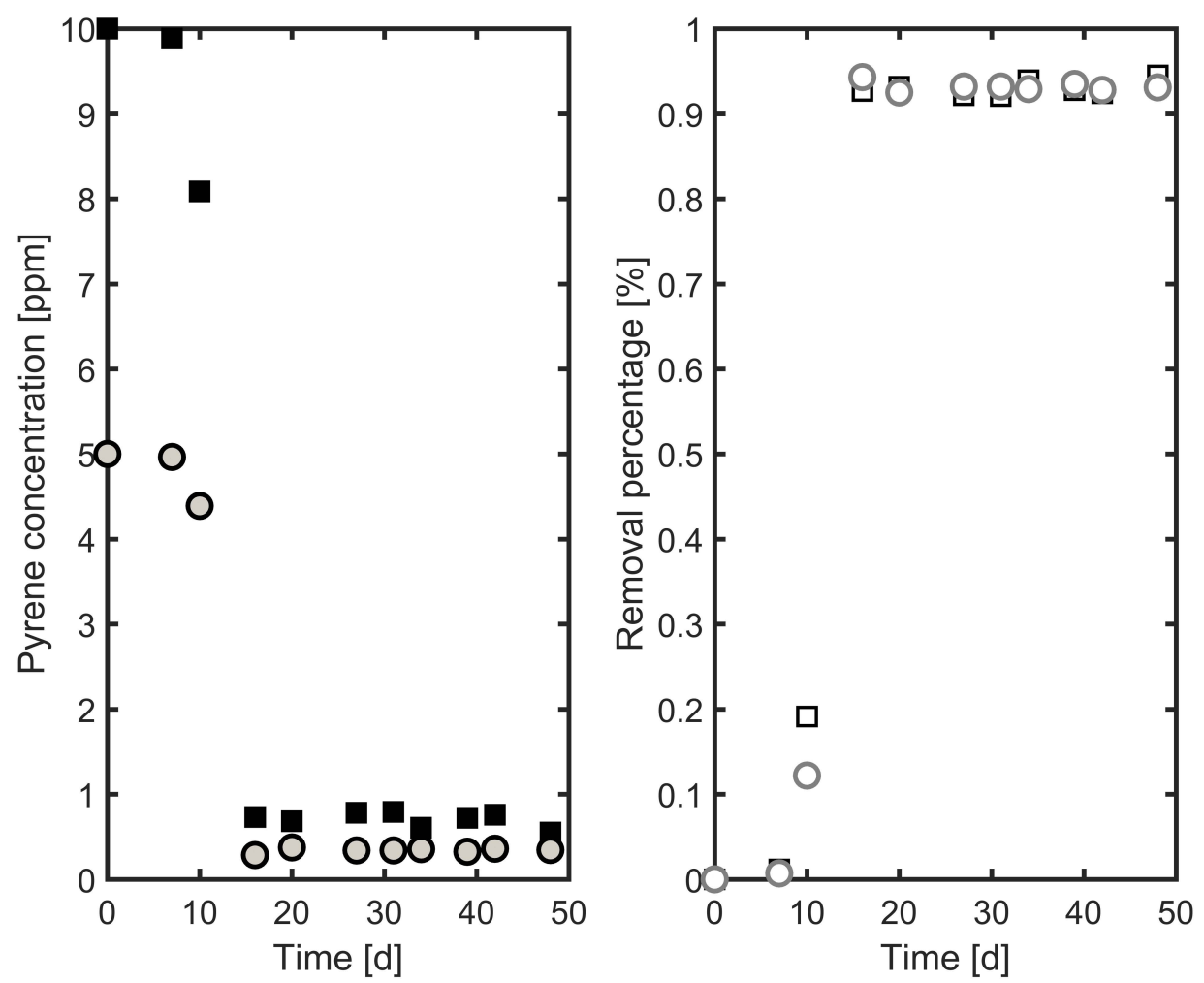

Fig. (7). Left side: Pyrene biodegradation starting from a solution of $10 \mathrm{ppm}$ (black solid square) and 5 ppm (grey solid circle). Right side: removal percentage from a solution of $10 \mathrm{ppm}$ (black square) and $5 \mathrm{ppm}$ (grey circle). 


\subsection{Biodegradation of Pyrene in Liquid Medium}

Biodegradation capability of Pleurotus sajor-caju was investigated by inoculating the mycelium in a liquid media. At this stage, pyrene was preferred to chrysene, since it was previously demonstrated to be better tolerated. Considering the effects revealed by the statistical analysis in the previous section, Tween $80(0.75 \%)$ and copper sulphate $(0.05 \mathrm{mM})$ were added to the medium. Biodegradation was assessed at two different concentration values of pyrene: 5 and $10 \mathrm{ppm}$.

Pyrene biodegradation profiles are reported in Fig. (7) for the two pollutant loads investigated. Results shows that the four-ring compound is almost transformed within 20 days, and that, for the investigated range, pyrene concentration does not significantly affect mycelium behaviour.

The profile of a possible metabolite detected through HPLC is reported in Fig. (8). Because it was not possible to identify this compound with the analytical instruments at our disposal, the area of chromatogram peaks for each sample is shown. The trends obtained at the different pyrene concentrations suggest that this compound is produced by mycelia during the degradation. The nature of this compound, as said previously, was not deeply investigated in this set of experiments; the compound possesses conjugated double bonds, as it appears by its UV absorbance, and it may derive from pyrene fungal metabolism. Further studies are to be performed to clarify the structure of the unknown compound, which is clearly produced only in the presence of pyrene, and to identify intermediates in order to determine a possible route of pyrene degradation by Pleurotus sajor-caju.

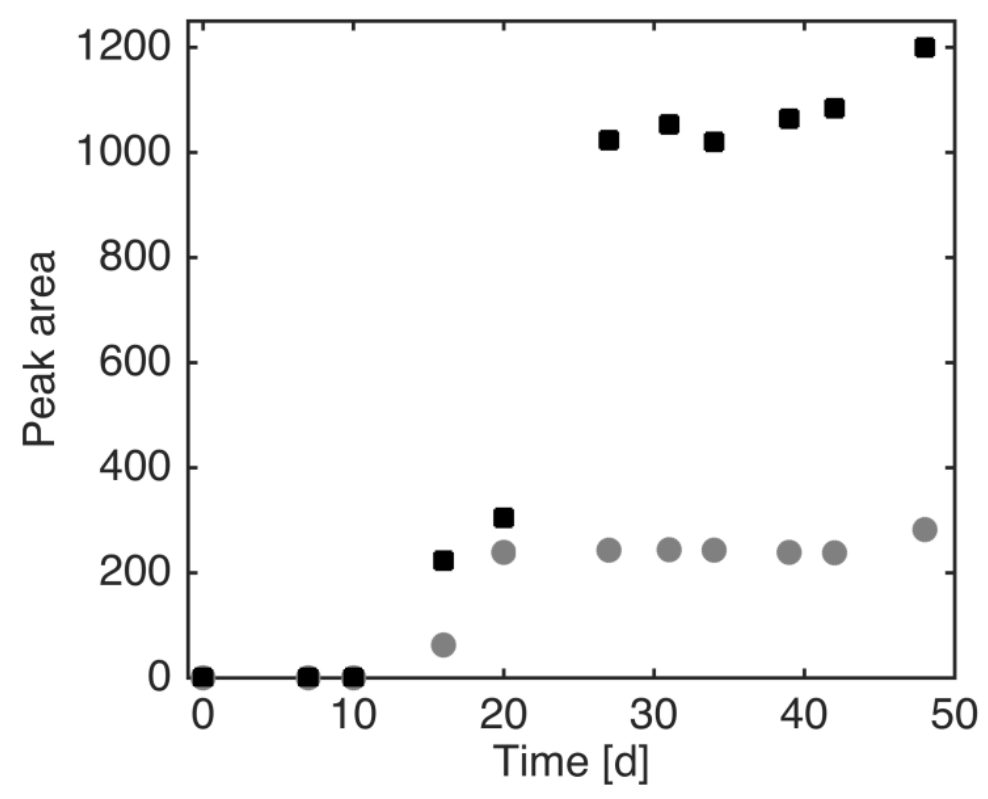

Fig. (8). Detected area for the biodegradation product for the solution with pyrene initial concentration equal to $10 \mathrm{ppm}$ (black square) and 5 ppm (grey circle).

\section{CONCLUSION}

Based on a fractional factorial design used to investigate the effects of different parameters, the growth in Petri dishes of Pleurotus sajor-caju evidenced that pyrene was well tolerated by the organism, and that Tween 80 and copper sulphate may enhance its development. The possibility to effectively degrade pyrene was then assessed by exposing the mycelium to the pollutant in a liquid medium, where pyrene was transformed within 20 days. It is important to underline that the absence of pyrene in the solid phase (mycelium) after 20 days was also assessed by GC-MS analysis, in order to be sure that the polycyclic hydrocarbon was definitely degraded by the organism. HPLC analysis evidenced that pyrene degradation was followed by formation of a metabolite, which could not be identified with the experimental apparatus at our disposal. Further studies are in progress for identifying the intermediates and metabolites of pyrene degradation and understanding the mechanism through which the fungus transforms the pollutant. 


\section{ETHICS APPROVAL AND CONSENT TO PARTICIPATE}

Not applicable.

\section{HUMAN AND ANIMAL RIGHTS}

No animals/humans were used for studies that are the basis of this review.

\section{CONSENT FOR PUBLICATION}

Not applicable.

\section{CONFLICT OF INTEREST}

The authors declare no conflict of interest, financial or otherwise.

\section{ACKNOWLEDGEMENTS}

Declared none.

\section{REFERENCES}

[1] E. Notomista, F. Pennacchio, V. Cafaro, G. Smaldone, V. Izzo, L. Troncone, M. Varcamonti, and A. Di Donato, "The marine isolate Novosphingobium sp. PP1Y shows specific adaptation to use the aromatic fraction of fuels as the sole carbon and energy source", Microb. Ecol., vol. 61, no. 3, pp. 582-594, 2011. [http://dx.doi.org/10.1007/s00248-010-9786-3] [PMID: 21258788]

[2] T. Hadibarata, A.R.M. Yusoff, A. Aris, and R.A. Kristanti, "Identification of naphthalene metabolism by white rot fungus Armillaria sp. F022", J. Environ. Sci. (China), vol. 24, no. 4, pp. 728-732, 2012 [http://dx.doi.org/10.1016/S1001-0742(11)60843-7] [PMID: 22894109]

[3] R. Carta, and F. Desogus, "The enhancing effect of low power microwaves on phenol oxidation by the Fenton process", J. Environ. Chem. Eng., vol. 1, no. 4, pp. 1292-1300, .

[http://dx.doi.org/10.1016/j.jece.2013.09.022]

[4] F.F. Martins, T.F. Ferreira, D.A. Azevedo, and M.A.Z. Coelho, "Evaluation of Crude Oil Degradation by Yarrowia lipolytica", Chem. Eng. Trans., vol. 27, pp. 223-228, 2012.

[5] G. Spigno, and S. Tronci, "Development of Hybrid Models for a Vapor-Phase Fungi Bioreactor", Math. Probl. Eng., 2015. [http://dx.doi.org/10.1155/2015/801213]

[6] C. Prasciolu, V. Perra, F. Desogus, S. Tronci, N. Curreli, G. Saiu, and M. Grosso, "Modelling and optimization of poly-aromatichydrocarbons biodegradation by Bulab 5738", Chem. Eng. Trans., vol. 57, pp. 337-342, 2017.

[7] G. Saiu, F. Poggi, S. Tronci, M. Grosso, A. Lallai, E. Cadoni, and N. Curreli, "Detection of parameters enhancing the performance of whiterot fungi for degradation of Poly-Aromatic Hydrocarbons through design-of-experiment methodologies", Chem. Eng. Trans., vol. 43, pp. 271-276, 2015.

[8] G. Saiu, S. Tronci, M. Grosso, E. Cadoni, and N. Curreli, N."Biodegradation of polycyclic aromatic hydrocarbons by pleurotus sajor-caju", Chem. Eng. Trans., vol. 49, pp. 487-492, 2016.

[9] P. Xiao, T. Mori, I. Kamei, H. Kiyota, K. Takagi, and R. Kondo, "Novel metabolic pathways of organochlorine pesticides dieldrin and aldrin by the white rot fungi of the genus Phlebia", Chemosphere, vol. 85, no. 2, pp. 218-224, 2011.

[http://dx.doi.org/10.1016/j.chemosphere.2011.06.028] [PMID: 21724225]

[10] O. Rubilar, G. Tortella, M. Cea, F. Acevedo, M. Bustamante, L. Gianfreda, and M.C. Diez, "Bioremediation of a Chilean Andisol contaminated with pentachlorophenol (PCP) by solid substrate cultures of white-rot fungi", Biodegradation, vol. 22, no. 1, pp. 31-41, 2011. [http://dx.doi.org/10.1007/s10532-010-9373-9] [PMID: 20512655]

[11] Z. Zhou, Y. Chen, X. Liu, K. Zhang, and H. Xu, "Interaction of copper and 2,4,5-trichlorophenol on bioremediation potential and biochemical properties in co-contaminated soil incubated with Clitocybe maxima", RSC Advances, vol. 5, no. 53, pp. 42768-42776, 2015. [http://dx.doi.org/10.1039/C5RA04861C]

[12] L. Gioia, C. Manta, K. Ovsejevi, J. Burgueño, and P. Menéndez, S. and Rodriguez-Couto, "Enhancing laccase production by a newly-isolated strain of Pycnoporus sanguineus with high potential for dye decolouration", RSC Advances, vol. 4, pp. 34096-34103, 2014. [http://dx.doi.org/10.1039/C4RA06039C]

[13] A.I. Rodarte-Morales, G. Feijoo, M.T. Moreira, and J.M. Lema, "Biotransformation of three pharmaceutical active compounds by the fungus Phanerochaete chrysosporium in a fed batch stirred reactor under air and oxygen supply", Biodegradation, vol. 23, no. 1, pp. 145-156, 2012. [http://dx.doi.org/10.1007/s10532-011-9494-9] [PMID: 21695453]

[14] H. Lee, S.Y. Yun, S. Jang, H. Kim, and J.J. Kim, "Bioremediation of polycyclic aromatic hydrocarbons in creosote-contaminated soil by peniophora incarnata KUC8836", Bioremediat. J., vol. 19, no. 1, pp. 1-8, 2015. [http://dx.doi.org/10.1080/10889868.2014.939136] 
[15] L. Valentìn, G. Feijoo, M.T. Moreira, and J.M. Lema, "Biodegradation of polycyclic aromatic hydrocarbons in forest and salt marsh solis by white-rot fungi", Int. Biodeterior. Biodegradation, vol. 58, pp. 15-21, 2006. [http://dx.doi.org/10.1016/j.ibiod.2006.04.002]

[16] S. Zhang, Y. Ning, X. Zhang, Y. Zhao, X. Yang, K. Wu, S. Yang, G. La, X. Sun, and X. Li, "Contrasting characteristics of anthracene and pyrene degradation by wood rot fungus Pycnoporus sanguineus H1", Int. Biodeterior. Biodegradation, vol. 105, pp. 228-232, 2015. [http://dx.doi.org/10.1016/j.ibiod.2015.09.012]

[17] G. Tortella, N. Durán, O. Rubilar, M. Parada, and M.C. Diez, "Are white-rot fungi a real biotechnological option for the improvement of environmental health?", Crit. Rev. Biotechnol., vol. 35, no. 2, pp. 165-172, 2015. [http://dx.doi.org/10.3109/07388551.2013.823597] [PMID: 24083453]

[18] A. Fraij, and M.I. Massadeh, "Use of Pleurotus sajor-caju for the Biotreatment of Olive Mill Wastewater", Rom. Biotechnol. Lett., vol. 20, no. 4, pp. 10611-10617, 2015.

[19] N. Curreli, A. Rescigno, A. Rinaldi, B. Pisu, F. Sollai, and E. Sanjust, "Degradation of juglone by Pleurotus sajor-caju", Mycol. Res., vol. 108, no. Pt 8, pp. 913-918, 2004. [http://dx.doi.org/10.1017/S0953756204000632] [PMID: 15449596]

[20] A. Gupta, S. Sharma, S. Saha, and S. Walia, "Yield and nutritional content of Pleurotus sajor caju on wheat straw supplemented with raw and detoxified mahua cake", Food Chem., vol. 141, no. 4, pp. 4231-4239, 2013. [http://dx.doi.org/10.1016/j.foodchem.2013.06.126] [PMID: 23993610]

[21] A.R. Ipeaiyeda, G.O. Nwauzor, and S.O. Akporido, "Biodegradation of Polycyclic Aromatic Hydrocarbons in Agricultural Soil Contaminated with Crude Oil from Nigeria Refinery using Pleurotus sajor-caju", J. Bioremediat. Biodegrad., vol. 6, no. 4, p. $301,2015$. [http://dx.doi.org/10.4172/2155-6199.1000301]

[22] T. Kadri, T. Rouissi, S. Kaur Brar, M. Cledon, S. Sarma, and M. Verma, "Biodegradation of polycyclic aromatic hydrocarbons (PAHs) by fungal enzymes: A review", J. Environ. Sci. (China), vol. 51, pp. 52-74, 2017. [http://dx.doi.org/10.1016/j.jes.2016.08.023] [PMID: 28115152]

[23] F. Bettin, L. Osorio da Rosa, Q. Montanari, R. Calloni, T. Aparecida Gaio, E. Malvessi, M. Moura da Silveira, and A.J. Pinheiro Dillon, "Growth kinetics, production, and characterization of extracellular laccases from Pleurotus sajor-caju PS-2001", Process Biochem., vol. 46, no. 3, pp. 758-764, 2011. [http://dx.doi.org/10.1016/j.procbio.2010.12.002]

[24] J.R. Hanson, The Chemistry of Fungi., Royal Society of Chemistry: Cambridge, UK, 2008.

[25] M. Bustamante, M.E. González, A. Cartes, and M.C. Diez, "Effect of soya lecithin on the enzymatic system of the white-rot fungi Anthracophyllum discolor", J. Ind. Microbiol. Biotechnol., vol. 38, no. 1, pp. 189-197, 2011. [http://dx.doi.org/10.1007/s10295-010-0844-0] [PMID: 20811924]

[26] F. Roch, and M. Alexander, "Biodegradation of hydrophobic compounds in the presence of surfactants", Environ. Toxicol. Chem., vol. 14, no. 7, pp. 1151-1158, 1995. [http://dx.doi.org/10.1002/etc.5620140705]

[27] K. Chen, Q. Zhu, Y. Qian, Y. Song, J. Yao, and M.M. Choi, "Microcalorimetric investigation of the effect of non-ionic surfactant on biodegradation of pyrene by PAH-degrading bacteria Burkholderia cepacia", Ecotoxicol. Environ. Saf., vol. 98, pp. 361-367, 2013. [http://dx.doi.org/10.1016/j.ecoenv.2013.08.012] [PMID: 24011930]

[28] J. Devore, and N. Farnum, Applied statistics for engineers and scientists., Duxbury Press: Pacific Grove, CA, 1999.

[29] D.C. Montgomery, Design and analysis of experiments., John Wiley \& Sons, Inc: Hoboken, NJ, 2013.

[30] G.E.P. Box, W.G. Hunter, and J.S. Hunter, Statistics for Experimenters., Wiley-Interscience: Hoboken, NJ, 1978.

[31] G.A.F. Seber, and C.J. Wild, Nonlinear regression., John Wiley \& Sons, Inc.: Hoboken, NJ, 2003.

[32] G. Cogoni, M. Grosso, R. Baratti, and J.A. Romagnoli, "Time evolution of the PSD in crystallization operations: An analytical solution based on Ornstein-Uhlenbeck process", AIChE J., vol. 58, no. 12, pp. 3731-3739, 2012. [http://dx.doi.org/10.1002/aic.13760]

[33] E. Morgan, Chemometrics, Open Learning in Experimental Design., Wiley: New York, USA, 1991.

\section{(C) 2018 Saiu et al.}

This is an open access article distributed under the terms of the Creative Commons Attribution 4.0 International Public License (CC-BY 4.0), a copy of which is available at: https://creativecommons.org/licenses/by/4.0/legalcode. This license permits unrestricted use, distribution, and reproduction in any medium, provided the original author and source are credited. 